DR PHILIP CASS is reviews editor of Pacific Journalism Review.

\section{Becoming a journalist in Nordic countries}

Becoming a Journalist, by Jan Fredrik Hovden, Gunnar Nygren and Henrika Zilliascus-Tikkanen (eds.). Goteburg: Nordicom, University of Goteborg.2016. 334pp. ISBN 978-1-91-87957-34-5

$\mathrm{P}$

UBLISHED through the Nordicom centre in Göteborg (Gothenburg), this study of journalism education in Denmark, Norway, Sweden, Finland and Iceland provides a comprehensive analysis of how future journalists are trained in Scandinavian universities.

While one might think this book would appeal to only a very specialised audience in this part of the world, it is worth reading to find out how countries with often similarly-sized populations, but very different societies, have developed in comparison.

Some interesting trends emerge from the study of young journalists. Across the Nordic countries there appears to be a decline of ideals of neutrality and objectivity, but more of a leaning towards investigative journalism and, interestingly, an increase in the number of students who think it would be acceptable for journalist to use their work for political purposes

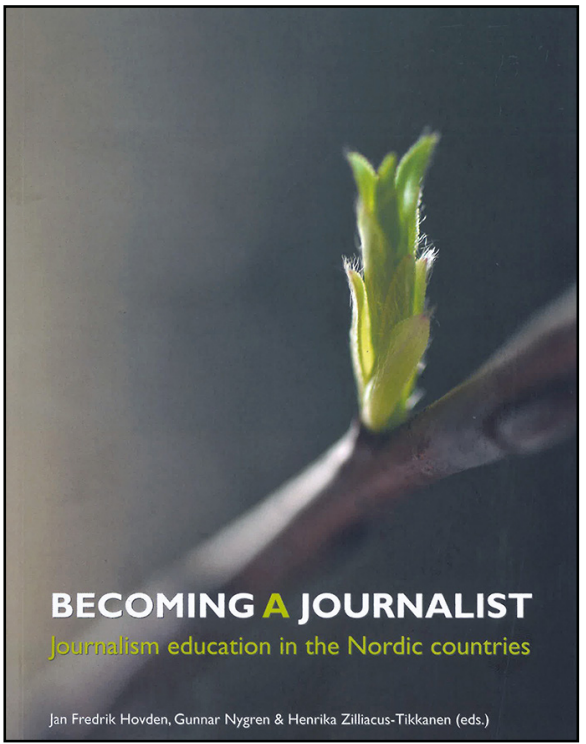

as against working journalists who see this as a violation of their neutrality.

Reflecting changes elsewhere in the world, students appear to be moving away from print as a career, but not in ways we might expect. In Denmark, a survey showed that while students were less interested in working for a national newspaper, this does not mean more of them wanted to work for web-based platforms; instead, they wanted to work for national television or magazines.

The book reflects debates about journalism education that will be familiar to any journalism educator; does one follow the hands-on, practical model followed at Aarhus University, or does one prefer the newer, more theoretical models favoured by the newer universities? In this respect, at least, the Nordic countries may have more in common with journalism educators in the Pacific than we might first think. 